\section{Suaeda glauca Can Be Produced Hydroponically at Moderate $\mathrm{NaCl}$ Salinity}

\author{
Yun Kong and Youbin Zheng ${ }^{1}$ \\ School of Environmental Sciences, University of Guelph, Guelph, ON, \\ Canada N1G 2W1; and Vineland Research and Innovation Centre, \\ Vineland, ON, Canada LOR 2EO
}

Additional index words. biomass accumulation, plant growth, sodium uptake, water consumption, $\mathrm{NaCl}$ concentration

\begin{abstract}
Suaeda glauca is an annual halophyte growing in saline-alkali environment in North China. To evaluate the potential of producing $S$. glauca as a vegetable at moderate $\mathrm{NaCl}$ concentrations, plants were grown in nutrient solutions with 6,8 , and $10 \mathrm{~mm} \mathrm{NaCl}$, and with $200 \mathrm{~mm} \mathrm{NaCl}$ as a control. Results showed that main stem length, true leaf number, side branch number, and canopy width of plants in 6-10 mM NaCl were not significantly different from those in $\mathbf{2 0 0} \mathrm{mm}$. Also, no significant differences in fresh and dry weights of individual plants, marketable yield, and water use efficiency of the plants were observed between 6-10 and $200 \mathrm{~mm} \mathrm{NaCl}$ treatments. Despite remarkable decreases in sodium uptake, similar water consumptions by the plants were obtained in 6-10 vs. $200 \mathrm{~mm} \mathrm{NaCl}$. The results suggest that $S$. glauca is a potential candidate for hydroponic production as a vegetable at moderate $\mathrm{NaCl}$ salinity, since growth attributes and biomass accumulation were not reduced when grown at lower salinity levels, despite with decreased sodium uptake.
\end{abstract}

Hydroponic vegetable growers are searching for ways to increase on-farm reuse of nutrient solutions and to reduce discharge into the environment (Shannon and Grieve, 2000). Discharge wastes both water and fertilizer, pollutes the environment, and can result in soil salinization (Varlagas et al., 2010). One of the most important factors limiting the reuse of nutrient solutions for hydroponic production of common vegetables (e.g., cucumber, tomato, and pepper) is elevated salinity (Van Os, 1998), resulting mainly from $\mathrm{Na}^{+}$and $\mathrm{Cl}^{-}$ accumulation attributable to their low uptake rates by these plant species (Kronzucker and Britto, 2011; Savvas et al., 2005).

One alternative strategy to discharging salinized solutions is to reuse them for hydroponic production of other economically valuable and more salt-tolerant crops (Grieve and Suarez, 1997; Kong and Zheng, 2014a; Pardossi et al., 1999). These types of crop species must have the ability to withstand elevated salinity levels without growth inhibition and reduced productivity, while providing a saleable product (Adler et al., 2003; Grieve and Suarez, 1997).

Suaeda glauca, an annual halophyte growing in saline-alkaline soils in North China

Received for publication 26 Feb. 2015. Accepted for publication 17 Apr. 2015.

We thank David Llewellyn, Tyson Jennett, Eric Rozema, and Katherine Vinson for their technical support and informative discussions during the experiment. Thanks also to the anonymous reviewers for their very useful suggestions on the revision of this manuscript.

${ }^{1}$ To whom reprint requests should be addressed; e-mail yzheng@uoguelph.ca.
(Guan et al., 2013), has a high degree of resistance to salt and alkali stresses (Yang et al., 2008). Consequently, it has been suggested $S$. glauca be used as pioneer plants for ecological recovery of saline and sodic soils (Guan et al., 2013). In addition, due to its good palatability and medicinal value (An et al., 2008; Yang et al., 2008), S. glauca has been identified as a traditional wild vegetable and/or medicinal plant in countries such as China and Korea (Kefu et al., 2002; Kim and Song, 2013). Moreover, S. glauca has recently been cultivated in China as one kind of seawater-irrigated specialty vegetable, which can be served as salad or stir-fried with other ingredients (Hong et al., 2003; Yancheng Green Garden Saline Soil Agricultural Science Co., 2013).

Can $S$. glauca be used for hydroponic production using salinized nutrient solutions recovered from the greenhouse production of the salt-intolerant vegetable crops mentioned above? To answer this question, it is necessary to assess at first the growth response of $S$. glauca to different salinity levels under hydroponic conditions. So far studies have been focused on mere evaluation of S. glauca's extreme salt tolerance and understanding tolerance mechanisms under soil or sand culture conditions while neglecting the crop's commercial potential (Guan et al., 2013; Sun and Zhou, 2010; Yang et al., 2008; Zhao et al., survive at soil salt concentrations equal to or greater than $2 \%(\approx 260 \mathrm{~mm} \mathrm{NaCl})$ (Sun and Zhou, 2010), but when root-zone $\mathrm{Na}^{+}$concentrations increased up to 300 and $450 \mathrm{~mm}$ under sand cultivation, the relative growth rate (RGR) and biomass began to show significant decrease (Guan et al., 2013; Yang et al., 2008). 2005). S. glauca has been reported to be able to
The high salt tolerance of $S$. glauca is associated with its high levels of salt accumulation in the plant tissues. In their native habitat, Xingjiang, China, the plant can accumulate $\mathrm{Na}^{+}$up to $2.2 \%$ of its dry weight (DW) (Zhao et al., 2005). Under sand cultivation, when external $\mathrm{Na}^{+}$concentrations increased from 75 to $300 \mathrm{~mm}, \mathrm{Na}^{+}$accumulation in fresh shoots increased from around 300 to $400 \mathrm{~mm}$ (Yang et al., 2008). However, salt tolerance, $\mathrm{Na}^{+}$ uptake, and biomass accumulation in plants can be affected by the culture medium (Liu, 2002) and no information is available for hydroponic conditions.

In the above studies, the $\mathrm{Na}^{+}$concentrations were relatively high; ranging from 75 to $600 \mathrm{~mm}$ (Guan et al., 2013; Yang et al., 2008). However, $\mathrm{Na}^{+}$concentration of most nutrient solutions discharged from hydroponic production of common vegetables ranges from 6 to $8 \mathrm{~mm}$, a moderate salinity (Van Os, 1998). Many dicotyledonous halophytes show optimal growth in concentrations of $50-250 \mathrm{~mm}$ $\mathrm{NaCl}$ (Flowers and Colmer, 2008), and suboptimal $\mathrm{NaCl}$ concentration may reduce plant growth of some halophytes in hydroponic systems (Rozema and Schat, 2013). For example, $5 \mathrm{~mm} \mathrm{NaCl}$ has been shown to reduce plant growth, including biomass accumulation, associated with decreased sodium uptake in hydroponic Salicornia bigelovii compared with $200 \mathrm{~mm} \mathrm{NaCl}$ (Ayala and O'Leary, 1995). Conversely, Brown et al. (1999) found that Suaeda esteroa, which is in the same genus as $S$. glauca, showed no significant differences in final DW and RGR between the plants treated by $\approx 9$ and $\approx 180 \mathrm{~mm} \mathrm{NaCl}$ under sand culture (Brown et al., 1999). However, S. esteroa and $S$. glauca are different halophyte species, and plant growth responses to salinity gradient may vary greatly among different halophyte species even in the same genus (Ashraf et al., 2010). Therefore, further study is needed to determine whether hydroponic $S$. glauca, like $S$. bigelovii, is negatively affected when cultivated in a low-salinity environment.

The overall objective of this study was to evaluate the potential of producing $S$. glauca hydroponically as a vegetable at moderate $(6-10 \mathrm{~mm}) \mathrm{NaCl}$ concentrations typically found in the discharged solutions from hydroponic production of common vegetables.

\section{Materials and Methods}

Plant materials and growing conditions. The experiments were conducted in a greenhouse in the Edmund C. Bovey building at the University of Guelph, Guelph, Ontario, Canada (lat. $43^{\circ} 33^{\prime} \mathrm{N}$, long. $80^{\circ} 15^{\prime} \mathrm{W}$ ). Seeds of $S$. glauca (bought from Yancheng Green Garden Saline Soil Agricultural Science Company, Jiangsu, China) were sown on 25 Apr. 2013, in a soilless medium with peatperlite mixture of $1: 1$ by volume. Twenty days after sowing, seedlings with three pairs of true leaves were transplanted into rockwool cubes $(3.8 \mathrm{~cm}$ Starter Plugs; Grodan Inc., Ontario, Canada), which were embedded in styrofoam discs floating on the nutrient 
solution in plastic pots (14 cm top and $12 \mathrm{~cm}$ bottom diameters $\times 15 \mathrm{~cm}$ high). Each pot had a styrofoam disc with four seedlings growing in individual rockwool cubes, except for the blank control pot that had only a disc and four unplanted rockwool cubes. Each pot contained $1.5 \mathrm{~L}$ of solution with the following nutrients (mg. $\mathrm{L}^{-1}$ ): $278.3 \mathrm{~N}, 36.7 \mathrm{P}, 420 \mathrm{~K}, 97.6 \mathrm{Ca}$, $1.58 \mathrm{Mg}, 100.8 \mathrm{~S}, 0.53 \mathrm{Cu}, 0.21 \mathrm{~B}, 0.53 \mathrm{Mn}$, $0.53 \mathrm{Zn}, 0.16 \mathrm{Mo}$, and $1.05 \mathrm{Fe}$. Seven days after transplanting, the nutrient solutions were changed for all the pots, and $\mathrm{NaCl}$ was added to the solutions to achieve four treatment concentrations: $6,8,10$, and 200 (control) $\mathrm{mm}$, which indicated the start of treatment. The initial $\mathrm{Na}^{+}$concentrations of the above four salt-treated nutrient solutions were measured as $6.9 \pm 0.1,8.8 \pm 0.2,10.8 \pm 0.3$, and $213.3 \pm 4.3 \mathrm{~mm}$, with the electrical conductivity of $3.34 \pm 0.03,3.54 \pm 0.05,3.81 \pm 0.06$, and $21.58 \pm 0.71 \mathrm{dS} \cdot \mathrm{m}^{-1}$, respectively. The nutrient solutions were changed every $7 \mathrm{~d}$ to reduce nutrient and $\mathrm{NaCl}$ concentration variability during the experiment and nutrient solution $\mathrm{pH}$ ranged between 5.5 and 7.0. Pots were arranged in a randomized block design with three blocks and four $\mathrm{NaCl}$ concentrations within each block.

The greenhouse conditions were set at $18-\mathrm{h}$ light/6-h dark by supplementing natural sunlight with high pressure sodium lamps to achieve a photosynthetic active radiation at canopy level averaging no less than $397 \pm 34$ $\mu \mathrm{mol} \cdot \mathrm{m}^{-2} \cdot \mathrm{s}^{-1}$, and 22 to $28^{\circ} \mathrm{C}$ light $/ 20$ to $22^{\circ} \mathrm{C}$ dark with a relative humidity between $50 \%$ and $60 \%$.

Measurement of plant growth. Two plants were randomly chosen from each pot within each block for growth measurements. Every week the following attributes were measured: main stem length, true leaf number, and side branch number on the main stem, and canopy width. Four weeks after the start of treatment, all the tested seedlings were harvested.

Plant fresh weight (FW) increase during each week was determined by weighing the solutions and plants at the beginning and the end of each week, since the rockwool and styrofoam weights were constant. Then, FW increase rate was calculated as follows:

$$
\begin{aligned}
& \text { FW increase rate }(\mathrm{g} / \text { plant } / \mathrm{d}) \\
& =\frac{\left(\mathrm{W}_{\mathrm{ft}}-\mathrm{W}_{\mathrm{fps}}\right)-\left(\mathrm{W}_{\mathrm{it}}-\mathrm{W}_{\mathrm{ips}}\right)}{4 \times \mathrm{t}}
\end{aligned}
$$

where $W_{\mathrm{ft}}$ and $W_{\text {it }}$ are the final and initial total weights $(\mathrm{g})$ of each pot together with solution, plants, rockwool cubes, and styrofoam during each week, respectively; $W_{\mathrm{fps}}$ and $W_{\text {ips }}$ are the final and initial weights (g) of each pot and solution during each week, respectively; $t$ is the treatment time (d) of each week, and 4 is the number of seedlings in each pot.

At the time of harvest each plant was cut at the base above the rockwool cube, and the remaining plant tissue was separated from the rockwool cube, washed with tap water, and then rinsed with deionized water. FW of plant tissue from above and within the rockwool cube were measured respectively. Plant tissue DWs were determined by drying in an oven at $65^{\circ} \mathrm{C}$ until constant weight was achieved.

Marketable yield and water use efficiency were calculated as follows:

Marketable yield $\left(\mathrm{kg} \cdot \mathrm{m}^{-2}\right)=\frac{\mathrm{FW}_{\mathrm{s}}}{1000 \times 0.015}$

where $\mathrm{FW}_{\mathrm{s}}$ is the fresh weight $(\mathrm{g})$ of harvested plant tissue above the rockwool cube from each pot and 0.015 is the top area $\left(\mathrm{m}^{2}\right)$ of each pot.

$$
\begin{aligned}
& \text { Water use efficiency }\left(\mathrm{g} \mathrm{FW} / \mathrm{L} \mathrm{H}_{2} \mathrm{O}\right) \\
& =\frac{\sum_{\mathrm{i}=1}^{4} \Delta \mathrm{FW}_{\mathrm{i}}}{\sum_{\mathrm{i}=1}^{4} \Delta \mathrm{V}_{\mathrm{i}}}
\end{aligned}
$$

where $\Delta \mathrm{FW}_{i}$ is the increase of fresh weight (g) of plants in each pot during the $i$ th week $(i=1,2,3$, and 4$)$, which can be estimated from Eq. [1], and $\Delta V_{i}$ is the volume (L) of consumed water in each pot during the $i$ th week $(i=1,2,3$, and 4$)$. The initial and final volume of nutrient solution was measured weekly per pot and the difference in solution volume was assumed to be the weekly volume of water consumed by the four plants in each pot.

Estimation of sodium uptake. A subsample of the fresh and week-old nutrient solution was analyzed for $\mathrm{Na}^{+}$concentration using a portable $\mathrm{pH} / \mathrm{ISE}$ meter and sodium electrode (Thermo Orion model 290A; Waltham, MA). $\mathrm{Na}^{+}$removal rate of the plants in each pot per week was calculated as follows:

$$
\begin{gathered}
\mathrm{Na}^{+} \text {removal rate }(\mathrm{mmol} / \text { plant/d }) \\
\left(\mathrm{V}_{\mathrm{i}} \times \mathrm{C}_{\mathrm{i}}-\mathrm{V}_{\mathrm{f}} \times \mathrm{C}_{\mathrm{f}}\right) \\
=\frac{-\left(\mathrm{V}_{\mathrm{i}}{ }^{\prime} \times \mathrm{C}_{\mathrm{i}}{ }^{\prime}-\mathrm{V}_{\mathrm{f}}{ }^{\prime} \times \mathrm{C}_{\mathrm{f}}{ }^{\prime}\right)}{4 \times \mathrm{t}}
\end{gathered}
$$

where $V_{\mathrm{i}}$ and $V_{\mathrm{f}}$ are the initial and final volumes $(\mathrm{L})$ of solution in each pot during each week, respectively; and $C_{\mathrm{i}}$ and $C_{\mathrm{f}}$ are the initial and final $\mathrm{Na}^{+}$concentrations (mM) in the solution in each pot during each week, respectively. $V_{\mathrm{i}}{ }^{\prime}, V_{\mathrm{f}}{ }^{\prime}, C_{\mathrm{i}}{ }^{\prime}$, and $C_{\mathrm{f}}{ }^{\prime}$ are the initial and final volumes (L) and the initial and final $\mathrm{Na}^{+}$concentrations (mM) of solution in blank control pot during each week, respectively. $t$ is the treatment time (d) of each week, and 4 is the number of seedlings in each pot.

At harvest, total $\mathrm{Na}^{+}$removal amount per plant was calculated as follows:

$$
\begin{aligned}
& \mathrm{Na}^{+} \text {removal amount (mmol/plant) } \\
& =\sum_{\mathrm{i}=1}^{4} \mathrm{SSR}_{\mathrm{i}} \times \mathrm{t}_{\mathrm{i}}
\end{aligned}
$$

where $\mathrm{SSR}_{i}$ is the $\mathrm{Na}^{+}$removal rate $(\mathrm{mmol} /$ plant/d) during the $i$ th week $(i=1,2,3$, and 4), which was determined from Eq. [4], and $t_{i}$ is the treatment time (d) during the $i$ th week $(i=1,2,3$, and 4). Equation [6] was used for the calculation of total water consumption of each plant (L/plant).

$$
\begin{aligned}
& \text { Water consumption (L/plant) } \\
& =\frac{\sum_{\mathrm{i}=1}^{4} \Delta \mathrm{V}_{\mathrm{i}}}{4}
\end{aligned}
$$

where $\Delta V_{i}$ has been defined in Eq. [3], and the denominator in the formula, 4 , is the number of seedlings in each pot.

$\mathrm{Na}^{+}$removal efficiency $\left(\mathrm{mol} \cdot \mathrm{kg}^{-1} \mathrm{DW}\right)$ and $\mathrm{Na}^{+}$uptake concentration $\left(\mathrm{mmol} \cdot \mathrm{L}^{-1} \mathrm{H}_{2} \mathrm{O}\right)$ were calculated as below:

$$
\begin{aligned}
& \mathrm{Na}^{+} \text {removal efficiency }\left(\mathrm{mol} \cdot \mathrm{kg}^{-1} \mathrm{DW}\right) \\
& =\frac{\mathrm{SRA}}{\mathrm{DW}}
\end{aligned}
$$

$\mathrm{Na}^{+}$uptake concentration $\left(\mathrm{mmol} \cdot \mathrm{L}^{-1} \mathrm{H}_{2} \mathrm{O}\right)$

$$
=\frac{\mathrm{SRA}}{\mathrm{WC}}
$$

In Eqs. [7] and [8], SRA is the total $\mathrm{Na}^{+}$ removal amount per plant (mmol/plant), which is determined from Eq. [5]. In Eq. [7], DW is the dry weight per plant (g/plant). In Eq. [8], WC is the total water consumption of each plant (L/plant), which can be determined from Eq. [6].

Statistical analysis. Data were subjected to analysis of variance using the Data Processing System Software (version 7.05; Refine Information Tech. Co., Hangzhou, China) and were presented as mean $\pm \mathrm{SE}$; separation of means was performed using Duncan's new multiple range test at the $P \leq 0.05$ level.

\section{Results}

Plant growth. Generally, there was no difference in apparent growth among the four $\mathrm{NaCl}$ treatments throughout the whole experimental period (Fig. 1), except that immediately before harvest $(27 \mathrm{~d}$ after the start of treatment) 6 and $8 \mathrm{~mm} \mathrm{NaCl}$ led to higher main stem length and side branch number than $200 \mathrm{~mm} \mathrm{NaCl}$ (Fig. 1A and C).

Biomass accumulation. The FW increase rate was similar among the four $\mathrm{NaCl}$ treatments during the first 3 weeks of treatment, but it was higher for plants in the $6-10 \mathrm{~mm}$ $\mathrm{NaCl}$ treatments than in the $200 \mathrm{~mm} \mathrm{NaCl}$ treatment during the week immediately before harvest (i.e., 21-28 d after the start of treatment) (Fig. 2). At harvest, fresh and dry weight of individual plants, marketable yield, and water use efficiency of the plants grown in $6-10 \mathrm{~mm} \mathrm{NaCl}$ showed no significant difference from those in $200 \mathrm{~mm} \mathrm{NaCl}$ (Table 1).

Sodium uptake. At the final harvest, significant decreases were observed in sodium uptake, but not in water consumption, by plants when solution concentrations of $\mathrm{NaCl}$ decreased from 200 to 6-10 $\mathrm{mm}$ (Table 2). Plants exposed to $6-10$ vs. $200 \mathrm{~mm} \mathrm{NaCl}$ 

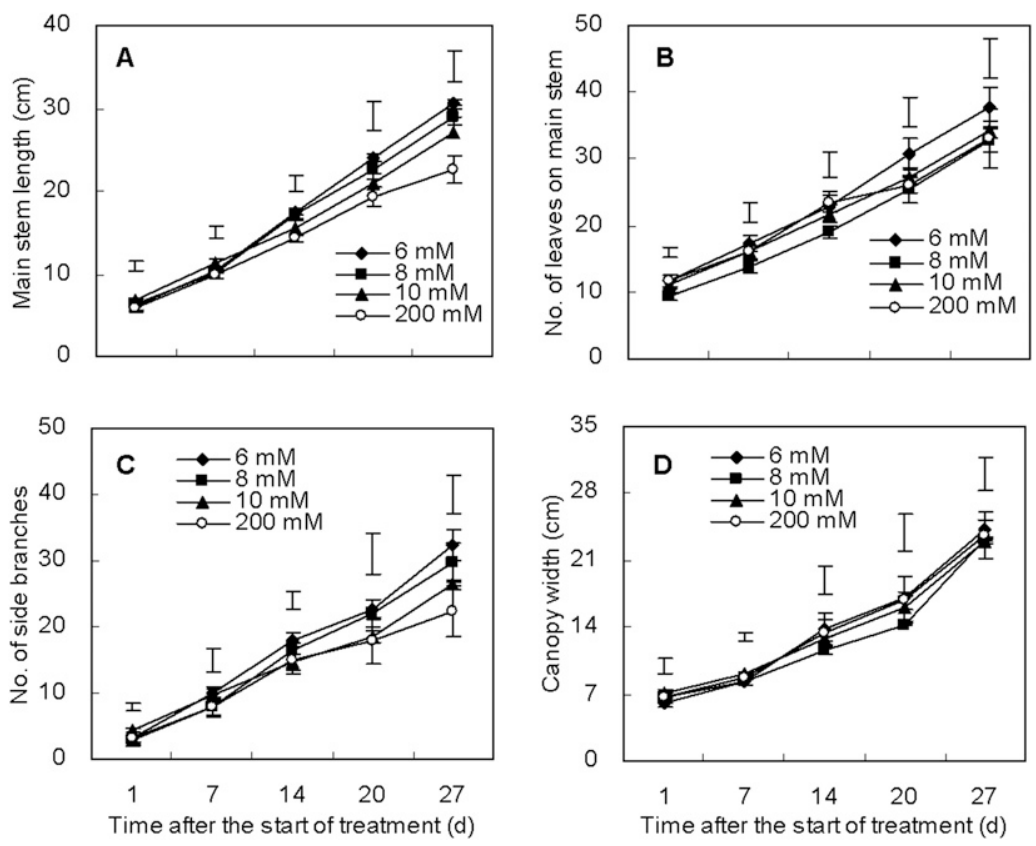

Fig. 1. Main stem length (A), number of leaves (B), number of side branches on main stem $(\mathbf{C})$, and canopy width (D) of $S$. glauca grown in hydroponic solutions with different $\mathrm{NaCl}$ concentrations and at different growth stages. Data are means $\pm \operatorname{SE}(n=6)$. Where bars are not visible, SE does not exceed the size of the symbol. The bars above the lines indicated the $\mathrm{LSD}_{0.05}$ for each measuring day.

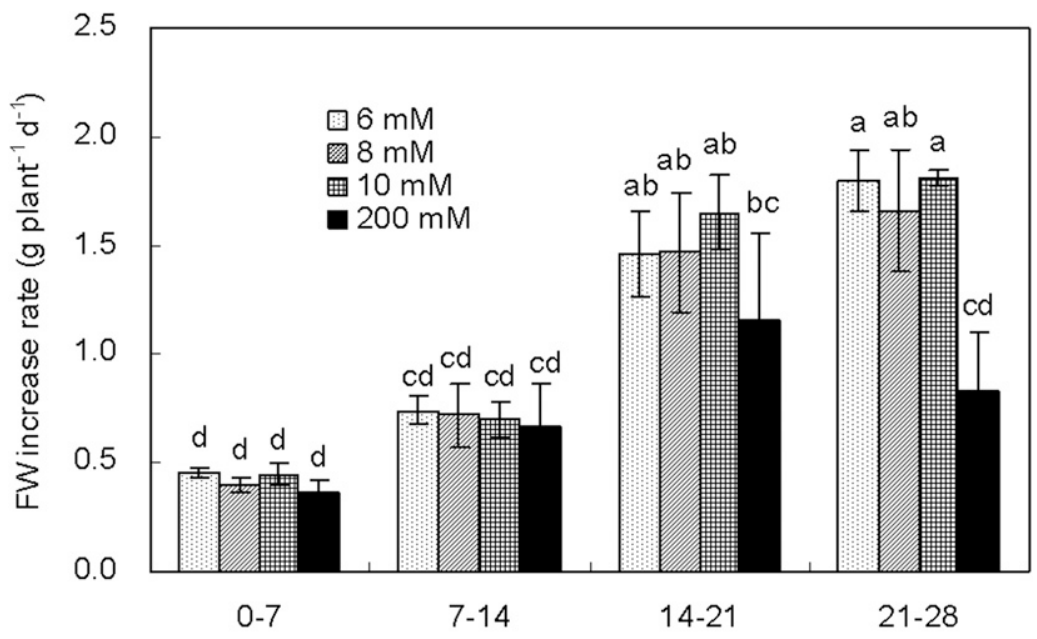

Time after the start of treatment $(d)$

Fig. 2. Fresh weight increase rate of $S$. glauca at different growth stages grown in hydroponic solutions with different $\mathrm{NaCl}$ concentrations. Data are means $\pm \mathrm{SE}(n=3)$. Bars bearing the same letter are not significantly different at $P \leq 0.05$ according to Duncan's new multiple range test.

showed $\approx 13-, 15-$, and 17 -fold decrease in $\mathrm{Na}^{+}$ removal amount, $\mathrm{Na}^{+}$removal efficiency, and $\mathrm{Na}^{+}$uptake concentration, respectively, but with similar water consumption.

\section{Discussion}

Moderate $\mathrm{NaCl}$ salinity did not reduce plant growth and biomass accumulation of hydroponic S. glauca. The optimal salinity levels for the growth of many halophytes have been shown to be $50-250 \mathrm{~mm} \mathrm{NaCl}$ (Flowers and Colmer, 2008). Suboptimal $\mathrm{NaCl}$ concentration may reduce plant growth, which is especially evident in hydroponic system studies; for example, 5-10 vs. $200 \mathrm{~mm}$ $\mathrm{NaCl}$ has reduced growth rate and biomass accumulation in hydroponic S. bigelovii (Ayala and O'Leary, 1995; Kong and Zheng, 2014b). However, unlike $S$. bigelovii, in the present study of hydroponic S. glauca, 6-10 mM $\mathrm{NaCl}$ did not inhibit plant growth compared with $200 \mathrm{~mm} \mathrm{NaCl}$. Similar results have been reported in $S$. esteroa under sand culture system where no significant differences in RGR and final DW were observed between the plants treated by $\approx 9$ and $\approx 180 \mathrm{~mm} \mathrm{NaCl}$ (Brown et al., 1999). It was suggested Suaeda generally performed better than Salicornia at moderate salinity.
The above differences in plant growth response to salinity gradient between Suaeda and Salicornia are possibly attributed to the fact that these two plant species are different types of halophytes (Ashraf et al., 2010). Salicornioideae and some other genera have been regarded as "obligate halophytes," since they do not just tolerate high salinity levels in hydroponic culture, but also require considerable salinity levels (e.g., $200 \mathrm{~mm}$ $\mathrm{NaCl}$ ) to attain optimal growth (Rozema and Schat, 2013). Evidently, "obligate halophytes" should include $S$. bigelovii, but not $S$. glauca as well as $S$. esteroa.

For leafy vegetables, yield potential greatly depends on biomass accumulation, and high growth rate (i.e., short production period) is one of the advantages of hydroponic production over soil cultivation (Kaşkar et al., 2008). No growth inhibition at $6-10$ vs. $200 \mathrm{~mm} \mathrm{NaCl}$ would not affect production time and yield potential for hydroponic $S$. glauca when grown under moderate vs. high $\mathrm{NaCl}$ concentrations.

Decreased $\mathrm{Na}^{+}$uptake in hydroponic $\mathrm{S}$. glauca at moderate $\mathrm{NaCl}$ salinity did not affect water consumption and biomass accumulation. The ability to accumulate $\mathrm{NaCl}$ for osmotic adjustment is a nearly universal trait of salttolerant plants (Glenn et al., 1999). However, $\mathrm{Na}^{+}$uptake from the medium by plants was positively related to $\mathrm{NaCl}$ concentration of root-zone solution, which might also affect the relative availability of $\mathrm{Na}^{+}$to the plant root system (Teixeira and Carvalho, 2008). Consequently, in the present study, when the external $\mathrm{NaCl}$ concentration decreased from 200 to 6-10 mM, S. glauca significantly reduced $\mathrm{Na}^{+}$absorption (Table 2 ).

Halophytes use the controlled uptake of $\mathrm{Na}^{+}$, balanced by $\mathrm{Cl}^{-}$and other anions, into cell vacuoles to drive water uptake into the plant against a low external water potential (Glenn et al., 1999). With the decrease of external $\mathrm{NaCl}$ concentrations, some halophytes like $S$. bigelovii not only decrease $\mathrm{Na}^{+}$absorption, but also reduce water consumption (Kong and Zheng, 2014b). However, water consumption by $S$. glauca was not reduced when external $\mathrm{NaCl}$ concentrations decreased from 200 to $6-10 \mathrm{~mm}$. This difference may be due to a less important role played by $\mathrm{Na}^{+}$in osmotic adjustment to drive water uptake into the plant at moderate salinity in Suaeda than in Salicornia. A previous study indicated that $\mathrm{Na}^{+}$was the major osmotica in Salicornia europaea leaves and its tissue $\mathrm{Na}^{+}$content was increased with higher levels of salinity, but Suaeda maritima plants accumulated higher levels of proline in their leaves at lower $\mathrm{NaCl}$ concentrations than $S$. europaea despite a similar tendency for the tissue $\mathrm{Na}^{+}$increase with increased external salinity (Moghaieb et al., 2004). Another study indicated that when external $\mathrm{Na}^{+}$concentration is low, succulent halophytes, such as S. maritima, also accumulate higher levels of $\mathrm{K}^{+}$(Flowers and Colmer, 2008).

The difference in water uptake response to salinity change between $S$. glauca and 
Table 1. Biomass accumulation, marketable yield, and water use efficiency in S. glauca grown in hydroponic solutions with different $\mathrm{NaCl}$ concentrations.

\begin{tabular}{ccccc}
\hline Added $\mathrm{NaCl}$ concn $(\mathrm{mM})$ & Fresh wt $(\mathrm{g} / \mathrm{plant})$ & Dry wt $(\mathrm{g} / \mathrm{plant})$ & Marketable yield $\left(\mathrm{kg} \cdot \mathrm{m}^{-2}\right)$ & Water use efficiency $\left(\mathrm{g}\right.$ FW/L $\left.\mathrm{H}_{2} \mathrm{O}\right)$ \\
\hline 6 & $24.7 \pm 1.8^{\mathrm{z}} \mathrm{a}^{\mathrm{y}}$ & $2.64 \pm 0.17 \mathrm{a}$ & $5.65 \pm 0.39 \mathrm{a}$ & $39.7 \pm 2.1 \mathrm{a}$ \\
8 & $23.9 \pm 1.6 \mathrm{a}$ & $2.47 \pm 0.33 \mathrm{a}$ & $5.57 \pm 0.43 \mathrm{a}$ & $36.1 \pm 0.4 \mathrm{a}$ \\
10 & $22.7 \pm 3.9 \mathrm{a}$ & $2.33 \pm 0.35 \mathrm{a}$ & $5.30 \pm 0.95 \mathrm{a}$ & $36.8 \pm 3.1 \mathrm{a}$ \\
200 & $16.5 \pm 4.8 \mathrm{a}$ & $2.17 \pm 0.51 \mathrm{a}$ & $4.02 \pm 1.14 \mathrm{a}$ & $32.9 \pm 5.0 \mathrm{a}$ \\
\hline
\end{tabular}

${ }^{\mathrm{z}}$ Data are means $\pm \mathrm{SE}(n=3)$.

${ }^{y}$ Different letters within a column denote significant differences $(P \leq 0.05)$ according to Duncan's new multiple range test.

Table 2. $\mathrm{Na}^{+}$removal amount, $\mathrm{Na}^{+}$removal efficiency, $\mathrm{Na}^{+}$uptake concentration, and water consumption $28 \mathrm{~d}$ after the start of treatment for $S$. glauca grown in hydroponic solutions with different $\mathrm{NaCl}$ concentrations.

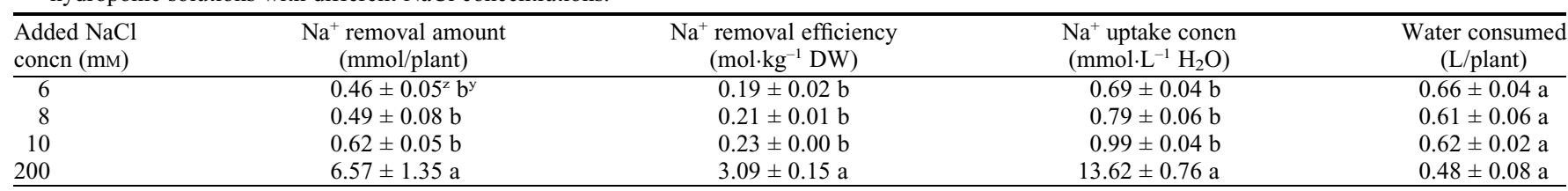

${ }^{2}$ Data are means \pm SE $(n=3)$

'Different letters within a column denote significant differences $(P \leq 0.05)$ according to Duncan's new multiple range test.

S. bigelovii could directly affect their plant succulence (i.e., amount of water per unit dry mass) and thereby biomass accumulation. When external $\mathrm{NaCl}$ concentrations decreased from 200 to $6-10 \mathrm{~mm}$, plant succulence was reduced in S. bigelovii (Kong and Zheng, 2014b), but not in $S$. glauca since this species showed no differences in both fresh and dry weight among different $\mathrm{NaCl}$ treatments. Both Suaeda and Salicornia are succulent halophytes (Brown et al., 1999), and succulence is not only a mechanism to dilute excess $\mathrm{NaCl}$ in leaf tissues (Glenn et al., 1999), but could also be a major contributor to biomass accumulation in these halophytes (Flowers and Colmer, 2008; Rozema and Schat, 2013). Consequently, when external $\mathrm{NaCl}$ concentration was lower, nonreduced succulence and water uptake in S. glauca, unlike in S. bigelovii, could contribute much to nonreduced biomass accumulation at moderate salinity, despite decreased $\mathrm{Na}^{+}$uptake in both plant species.

In summary, our results suggest that, at moderate $\mathrm{NaCl}$ salinity, $S$. glauca has the potential to be used for hydroponic production as a vegetable due to nonreduced plant growth and yield, despite decreased $\mathrm{Na}^{+}$uptake.

\section{Literature Cited}

Adler, P.R., S.T. Summerfelt, D.M. Glenn, and F. Takeda. 2003. Mechanistic approach to phytoremediation of water. Ecol. Eng. 20:251-264.

An, R.-B., D.-H. Sohn, G.-S. Jeong, and Y.-C. Kim. 2008. In vitro hepatoprotective compounds from Suaeda glauca. Arch. Pharm. Res. 31:594-597.

Ashraf, M., M. Ozturk, and M.S.A. Ahmad. 2010. Plant adaptation and phytoremediation. Springer, New York.

Ayala, F. and J.W. O'Leary. 1995. Growth and physiology of Salicornia bigelovii Torr. at suboptimal salinity. Intl. J. Plant Sci. 156:197-205.

Brown, J.J., E.P. Glenn, K.M. Fitzsimmons, and S.E. Smith. 1999. Halophytes for the treatment of saline aquaculture effluent. Aquaculture 175:255-268.
Flowers, T.J. and T.D. Colmer. 2008. Salinity tolerance in halophytes. New Phytol. 179:945-963.

Glenn, E.P., J.J. Brown, and E. Blumwald. 1999. Salt tolerance and crop potential of halophytes. Crit. Rev. Plant Sci. 18:227-255.

Grieve, C.M. and D.L. Suarez. 1997. Purslane (Portulaca oleracea L.): A halophytic crop for drainage water reuse systems. Plant Soil 192:277-283.

Guan, B., Q. Lin, D. Zhou, and J. Yu. 2013. Germination strategies of Suaeda species for saline-alkaline environments. Afr. J. Agr. Res. 8:690-694.

Hong, L., C. Zhou, M. Wang, J. Ding, and J. Yin. 2003. Cultivation techniques for Suaeda glauca. China Vegetables. 3:52.

Kaşkar, Ç., J.A. Fernándeza, J. Ochoa, D. Niñirola, E. Conesa, and Y. Tüzel. 2008. Agronomic behaviour and oxalate and nitrate content of different purslane cultivars (Portulaca oleracea) grown in a hydroponic floating system. Acta Hort. 807:521-526.

Kefu, Z., F. Hai, and I.A. Ungar. 2002. Survey of halophyte species in China. Plant Sci. 163:491498.

Kim, H. and M.-J. Song. 2013. Ethnobotanical analysis for traditional knowledge of wild edible plants in North Jeolla Province (Korea). Genet. Resources Crop Evol. 60:1571-1585.

Kong, Y. and Y. Zheng. 2014a. Hydroponic production of purslane as a sodium-removing vegetable in $\mathrm{NaCl}$-rich nutrient solution. HortScience 49:201-206.

Kong, Y. and Y. Zheng. 2014b. Potential of producing Salicornia bigelovii hydroponically as a vegetable at moderate $\mathrm{NaCl}$ salinity. HortScience 49:1154-1157.

Kronzucker, H.J. and D.T. Britto. 2011. Sodium transport in plants: A critical review. New Phytol. 189:54-81.

Liu, S. 2002. Modern and practical soilless cultivation technology. China Agricultural Press, Beijing.

Moghaieb, R.E.A., H. Saneoka, and K. Fujita. 2004. Effect of salinity on osmotic adjustment, glycinebetaine accumulation and the betaine aldehyde dehydrogenase gene expression in two halophytic plants, Salicornia europaea and Suaeda maritima. Plant Sci. 166:1345-1349.
Pardossi, A., G. Bagnoli, F. Malorgio, C.A. Campiotti, and F. Tognoni. 1999. NaCl effects on celery (Apium graveolens L.) grown in NFT. Sci. Hort. 81:229-242.

Rozema, J. and H. Schat. 2013. Salt tolerance of halophytes, research questions reviewed in the perspective of saline agriculture. Environ. Exp. Bot. 92:83-95.

Savvas, D., V.A. Pappa, G. Gizas, and L. Maglaras. 2005. Influence of $\mathrm{NaCl}$ concentration in the irrigation water on salt accumulation in the root zone and yield in a cucumber crop grown in a closed hydroponic system. Acta Hort. 697:93-98.

Shannon, M.C. and C.M. Grieve. 2000. Options for using low-quality water for vegetable crops. HortScience 35:1058-1062.

Sun, H.X. and D.W. Zhou. 2010. Effect of dietary supplement of seed of a halophyte (Suaeda glauca) on feed and water intake, diet digestibility, animal performance and serum biochemistry in lambs. Livest. Sci. 128:133-139.

Teixeira, M. and I.S. Carvalho. 2008. Effects of salt stress on purslane (Portulaca oleracea) nutrition. Ann. Appl. Biol. 154:77-86.

Van Os, E.A. 1998. Closed soilless growing systems in The Netherlands: The finishing touch. Acta Hort. 458:279-292.

Varlagas, H., D. Savvas, G. Mouzakis, C. Liotsos, I. Karapanos, and N. Sigrimis. 2010. Modelling uptake of $\mathrm{Na}^{+}$and $\mathrm{Cl}^{-}$by tomato in closedcycle cultivation systems as influenced by irrigation water salinity. Agr. Water Mgt. 97:1242-1250.

Yancheng Green Garden Saline Soil Agricultural Science Co. L. 2013. Fresh Suaeda Glauca. Jan. 14. 2015. <http://www.21 food.com/show$\mathrm{room} / 732703 /$ product/fresh-suaeda-glauca. html>

Yang, C., D. Shi, and D. Wang. 2008. Comparative effects of salt and alkali stresses on growth, osmotic adjustment and ionic balance of an alkali-resistant halophyte Suaeda glauca (Bge.). Plant Growth Regulat. 56:179-190.

Zhao, K.-F., H. Fan, J. Song, M.-X. Sun, B.-Z. Wang, S.-Q. Zhang, and I.A. Ungar. 2005. Two $\mathrm{Na}^{+}$and $\mathrm{Cl}^{-}$hyperaccumulators of the Chenopodiaceae. J. Integr. Plant Biol. 47:311318. 